\title{
GPS geodetic infrastructure for subsidence and fault monitoring in Houston, Texas, USA
}

\author{
Gonzalo Agudelo ${ }^{1}$, Guoquan Wang ${ }^{1}$, Yuhao Liu ${ }^{1}$, Yan $\mathrm{Bao}^{2}$, and Michael J. Turco \\ ${ }^{1}$ Department of Earth and Atmospheric Sciences, University of Houston, Houston, Texas 77204, USA \\ ${ }^{2}$ The Key Laboratory of Urban Security and Disaster Engineering of Ministry of Education, \\ Beijing University of Technology, Beijing 100124, China \\ ${ }^{3}$ Harris-Galveston Subsidence District, Friendswood, Texas 77546, USA
}

Correspondence: Guoquan Wang (gwang@uh.edu)

Published: 22 April 2020

\begin{abstract}
Houston, Texas, is one of the earliest urban areas to employ Global Positioning System (GPS) technology for land subsidence and fault monitoring. As of 2020, the University of Houston and the Harris-Galveston Subsidence District have integrated over 230 permanent GPS stations into their routine GPS data processing for regional subsidence and fault monitoring. This article summarizes the GPS geodetic infrastructure in the Greater Houston region. The infrastructure is comprised of two components: a dense GPS network (HoustonNet) and a stable regional reference frame (Houston20). Houston20 is realized by 25 long-history ( $>8$ years) continuous GPS stations located outside the subsiding area and is aligned in origin and scale with the International GNSS Reference Frame 2014 (IGS14). The stability of the regional reference frame is below $1 \mathrm{~mm} \mathrm{yr}^{-1}$ in all three directions. GPS-derived ground deformation rates (2010-2019) within the Greater Houston region are also presented in this article.
\end{abstract}

\section{Introduction}

For over 100 years, the city of Houston, along with the greater metropolitan region, have been impacted by land subsidence and fault movements. The Greater Houston region covers an area of approximately $22500 \mathrm{~km}^{2}(150 \mathrm{~km}$ by $150 \mathrm{~km}$ ) and centers on Harris County (Fig. 1), the thirdmost populous county in the U.S. The Chicot, Evangeline, and Jasper aquifers are the major aquifers underlying the Greater Houston region. Land subsidence in this region is primarily caused by the compaction of clay lenses in the Chicot and Evangeline aquifers throughout the region and the Jasper aquifer in the northern part of the region due to groundwater withdrawal (e.g., Kearns et al., 2015; Turco et al., 2015; Kasmarek and Ramage, 2017; Qu et al., 2019). Ground deformation associated with subsidence and faulting has caused widespread damage to residential, commercial, industrial buildings, and public infrastructure since the 1950s. Long-term subsidence also increases the flooding risk, which has a particular concern in many areas within
Houston along with low-lying areas near the bayous and Gulf coast. To prevent land subsidence that contributes to flooding and infrastructure damages, the Texas Legislature created the Harris-Galveston Subsidence District (HGSD) in 1975 and the Fort Bend Subsidence District (FBSD) in 1989 to regulate groundwater withdrawal in areas within their respective jurisdictions. Subsequent to establishing these two subsidence districts, the Texas State Legislature established two groundwater conservation districts, Lone Star Groundwater Conservation District (LSGCD) (2001) and Brazoria County Groundwater Conservation District (BCGCD) (2005). These were created to conserve, protect, and regulate groundwater resources in Montgomery County and Brazoria County.

Accurate and long-term monitoring of ground deformation is critical to establishing effective groundwater regulations for mitigating damages due to subsidence and faulting. Prior to the 1990s, subsidence within the Houston area was measured using levelling surveys and extensometers. The Global Positioning System (GPS) has gradually replaced conventional levelling surveying and has become the primary tool 


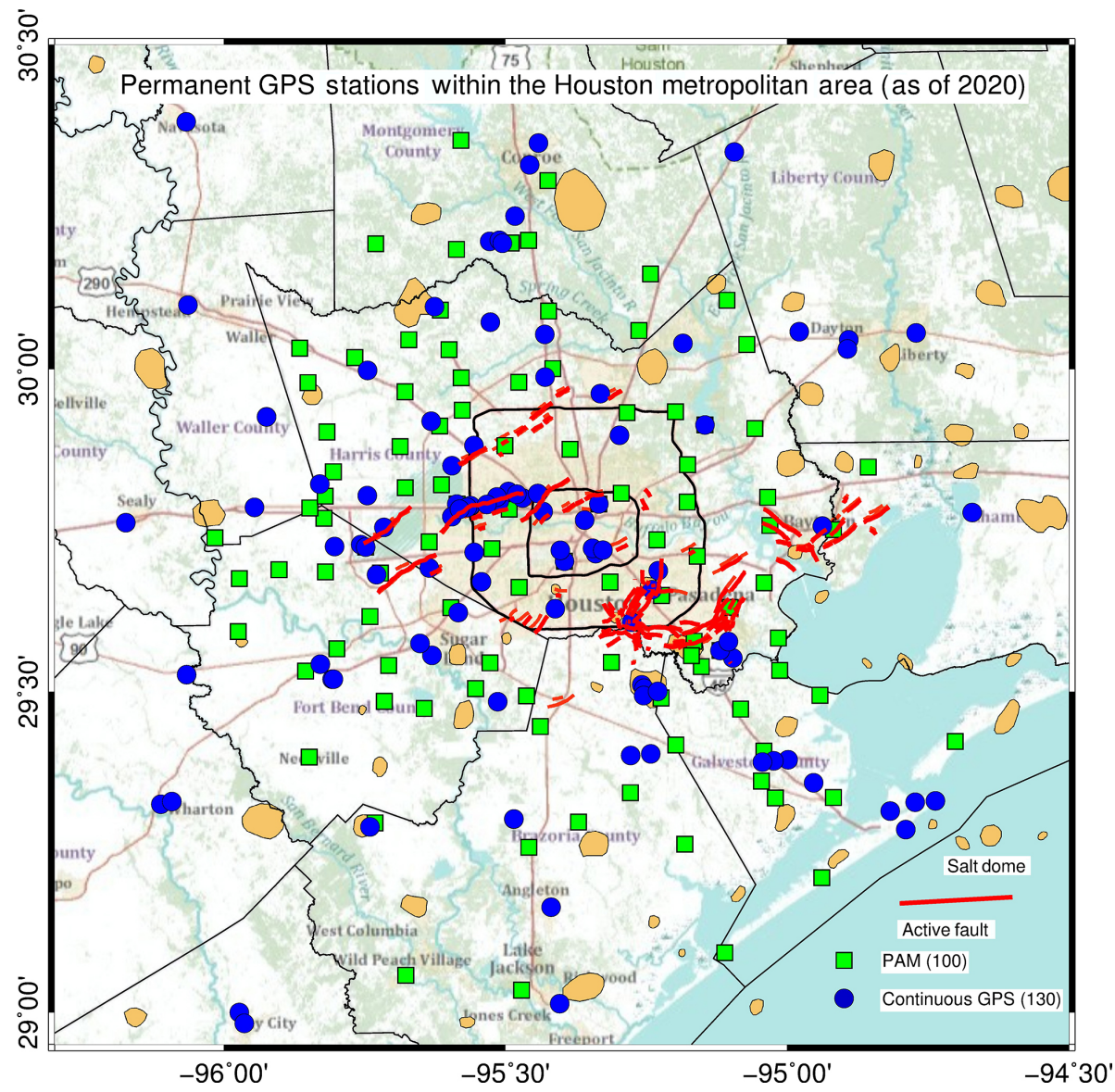

Figure 1. HoustonNet permanent GPS stations in the Greater Houston region as of early 2020. The red lines represent active faults mapped by USGS (Shah and Lanning-Rush, 2005); the orange filled polygons represent salt domes mapped by USGS (Huffman et al., 2004).

for subsidence monitoring in the Greater Houston region since the 1990s.

The accuracy of GPS measurements (site velocities) does not solely rely on GPS equipment (antennas and receivers), but largely depends on the available regional geodetic infrastructure, which can be defined by two fundamental components: a dense continuous long-history GPS network and a stable regional reference frame. The former is often referred to as the hardware component and the latter is referred to as the firmware component of a geodetic infrastructure. This article aims to expound the geodetic infrastructure within the Greater Houston region as of 2020.

\section{HoustonNet: a permanent GPS network consisting of over 230 stations}

In the early 1990s, HGSD established a surveying network of approximately 20 permanent GPS stations for the purpose of subsidence monitoring. These GPS sites are also called PortA-Measure (PAM) stations (Zilkoski et al., 2003). PAM stations were installed on free-field and designed as a campaignstyle long-term GPS monitoring solution. On average, the
GPS data was continuously collected for one week per month at each PAM site prior to 2005 and one week every two months since 2005 . The PAM network has continuously expanded, reaching 100 total stations in 2019. In addition to the PAM GPS network, there are currently over 130 continuously operating GPS stations within the Greater Houston region. These continuous GPS stations are installed on free-fields or one- to two-story buildings and are operated by joint efforts of the University of Houston (UH), Texas Department of Transportation (TxDOT), National Geodetic Survey (NGS) at the National Oceanic and Atmospheric Administration (NOAA), SmartNet, the City of Houston, and other agencies.

UH and HGSD have integrated over 230 permanent GPS stations within the Greater Houston region into their routine data processing and analysis for subsidence and fault monitoring (Fig. 1). This collection of GPS stations forms a network called HoustonNet. 


\section{A stable regional reference frame: Houston20}

GPS positions are initially provided as a set of coordinates with respect to a global reference frame. In general, a global geodetic reference frame is realized with an approach of minimizing the overall movements of a group of selected reference stations distributed worldwide. As a result, the GPSderived movements at a site with respect to a global reference frame are often dominated by factors such as the long-term drift and rotation of the tectonic plate on which the site is located, glacial isostatic adjustment, and other minor secular motions (Wang et al., 2020). Localized and temporal ground deformation, such as subsidence and fault creeping, could be obscured or biased by those common motions. A stable regional reference frame is designed to exclude those common ground motions and highlight localized ground deformation.

\subsection{Reference stations}

In the surveying and geodesy community, a regional reference frame is often developed through a simultaneous Helmert transformation from a well-established and broadly used global reference frame. A group of common points, known as reference stations, are used to link these two reference frames. A stable Houston reference frame was initially established in 2013 and tied to the International GNSS Service (IGS) Reference Frame 2008 (Wang et al., 2013). The regional reference frame firstly provided a platform to integrate long-history GPS datasets collected by number of agencies in various areas with different equipment into a uniform reference frame. The initial reference frame was updated in 2015 by adding approximately two more years of observations from 10 reference stations (Wang et al., 2015). A recent update was completed in 2016 with over 7 years of continuous observations from 15 reference stations (Kearns et al., 2019), which was designated as Houston16. IGS updated its official reference frame from IGS08 to IGS14 in 2017 (Rebischung et al., 2016). Consequently, the reference frame of all IGS satellite orbit products was updated to IGS14. JPL's GipsyX software package (Version 1.2) is employed to calculate single-receive phase-ambiguity-fixed Precise Point Positioning (PPP) solutions for our routine processing (Bertiger et al., 2010). The PPP solutions are aligned to IGS14. Thus, a local reference frame tied to IGS14 is needed.

This study updates Houston 16 by removing stations that are no longer in operation or have poor data quality, while adding additional reference stations to improve the overall geographic distribution and data redundancy (Fig. 2). Since GPS data as available in early 2020 is used for realizing the reference frame, the updated reference frame is designated as Houston20. The detailed methods for realizing a stable regional reference frame and the criteria for selecting reference stations are addressed in recent publications for establishing regional reference frames in North China (Wang et al., 2018),

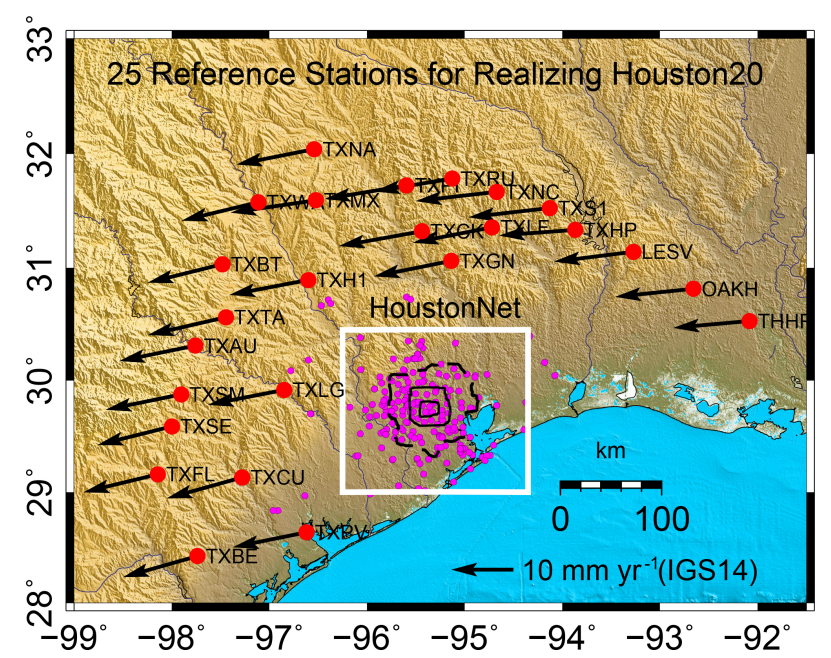

Figure 2. Locations and horizontal velocity vectors (referred to IGS14) of 25 reference stations utilized to realize Houston 20.

Houston (Kearns et al., 2019), and the Caribbean (Wang et al., 2019).

\subsection{Realization of Houston20}

The original PPP solutions are defined in an Earth-CenteredEarth-Fixed (ECEF) Cartesian coordinate system that represents a position as a pair of $X, Y$, and $Z$ coordinates. The ECEF-XYZ coordinates with respect to Houston 20 can be obtained by the following transformation, Eq. (1)

$$
\begin{aligned}
X(t)_{\mathrm{H} 20}= & X(t)_{\mathrm{IGS} 14}+T_{x}^{\prime} \cdot\left(t-t_{0}\right)+R_{z}^{\prime} \cdot\left(t-t_{0}\right) \\
& \cdot Y(t)_{\mathrm{IGS} 14}-R_{y}^{\prime} \cdot\left(t-t_{0}\right) \cdot Z(t)_{\mathrm{IGS} 14} \\
Y(t)_{\mathrm{H} 20}= & Y(t)_{\mathrm{IGS} 14}+T_{y}^{\prime} \cdot\left(t-t_{0}\right)-R_{z}^{\prime} \cdot\left(t-t_{0}\right) \\
& \cdot X(t)_{\mathrm{IGS} 14}+R_{x}^{\prime} \cdot\left(t-t_{0}\right) \cdot Z(t)_{\mathrm{IGS} 14} \\
Z(t)_{\mathrm{H} 20}= & Z(t)_{\mathrm{IGS} 14}+T_{z}^{\prime} \cdot\left(t-t_{0}\right)+R_{y}^{\prime} \cdot\left(t-t_{0}\right) \\
& \cdot X(t)_{\mathrm{IGS} 14}-R_{x}^{\prime} \cdot\left(t-t_{0}\right) \cdot Y(t)_{\mathrm{IGS} 14}
\end{aligned}
$$

where $X(t)_{\mathrm{IGS} 14}, Y(t)_{\mathrm{IGS} 14}$, and $Z(t)_{\mathrm{IGS} 14}$ are the ECEFXYZ coordinates (at epoch $t$ ) of a site with respect to the global reference frame IGS14; $X(t)_{\mathrm{H} 20}, Y(t)_{\mathrm{H} 20}$, and $Z(t)_{\mathrm{H} 20}$ are the ECEF-XYZ coordinates of the site with respect to Houston20 at epoch $t$. The daily positions with respect to IGS14 $\left(X(t)_{\mathrm{IGS} 14}, Y(t)_{\mathrm{IGS} 14}, Z(t)_{\mathrm{IGS} 14}\right)$ can be obtained by the PPP processisng. The units of these $X Y Z$ coordinates are meters. $t_{0}$ is the epoch that aligns the coordinates with respect to these two reference frames. $t_{0}$ is fixed at 2016.0 (year) for Houston20. A site retains identical $X Y Z$ coordinates at epoch 2016.0 with respect to IGS14 and Houston20. $T_{x}^{\prime}, T_{y}^{\prime}, T_{z}^{\prime} R_{x}^{\prime}, R_{y}^{\prime}$, and $R_{z}^{\prime}$ are constant parameters indicating the rates (one-time derivates) of three translational shifts and three rotations between two reference frames along the $x, y$, $z$ coordinate axes. These seven parameters: $t_{0}, T_{x}^{\prime}, T_{y}^{\prime}, T_{z}^{\prime}, R_{x}^{\prime}$, $R_{y}^{\prime}$, and $R_{z}^{\prime}$, are listed in Table 2 . 
Table 1. Site velocities of 25 reference stations.

\begin{tabular}{|c|c|c|c|c|c|c|c|c|}
\hline \multirow[t]{2}{*}{$\begin{array}{l}\text { Ref. } \\
\text { GPS }\end{array}$} & \multicolumn{2}{|c|}{$\begin{array}{l}\text { Location } \\
\text { (Degree) }\end{array}$} & \multicolumn{3}{|c|}{$\begin{array}{c}\text { Site Velocity } \\
(\mathrm{IGS} 14)\left(\mathrm{mm} \mathrm{yr}^{-1}\right)\end{array}$} & \multicolumn{3}{|c|}{$\begin{array}{c}\text { Site Velocity } \\
(\text { Houston } 20)^{*}\left(\mathrm{~mm} \mathrm{yr}^{-1}\right)\end{array}$} \\
\hline & Long. & Lat. & EW & NS & UD & EW & NS & UD \\
\hline LESV & -93.269 & 31.142 & -12.8 & -1.6 & -1.2 & -0.2 & -0.1 & 0.9 \\
\hline OAKH & -92.657 & 30.816 & -12.6 & -1.3 & -3.0 & -0.1 & -0.1 & -0.7 \\
\hline THHR & -92.081 & 30.529 & -12.3 & -1.1 & -0.8 & 0.1 & 0.0 & 1.6 \\
\hline TXAU & -97.756 & 30.312 & -12.3 & -2.5 & -1.3 & 0.1 & 0.4 & -0.2 \\
\hline TXBE & -97.735 & 28.424 & -12.0 & -3.4 & -1.4 & -0.1 & -0.4 & -0.4 \\
\hline TXBT & -97.479 & 31.033 & -12.1 & -3.0 & -2.0 & 0.5 & -0.1 & -0.6 \\
\hline TXCK & -95.436 & 31.323 & -13.4 & -2.4 & -1.3 & -0.7 & -0.2 & 0.4 \\
\hline TXCU & -97.276 & 29.134 & -12.2 & -3.4 & -1.8 & -0.1 & -0.5 & -0.7 \\
\hline TXFL & -98.142 & 29.161 & -12.0 & -2.9 & 0.2 & 0.1 & 0.2 & 1.2 \\
\hline TXGN & -95.136 & 31.061 & -12.5 & -2.5 & -2.1 & 0.1 & -0.4 & -0.7 \\
\hline TXH1 & -96.602 & 30.893 & -12.7 & -2.4 & -1.6 & -0.1 & 0.2 & -0.1 \\
\hline TXHP & -93.865 & 31.334 & -12.3 & -0.9 & -2.9 & 0.4 & 0.7 & -1.5 \\
\hline TXLF & -94.718 & 31.356 & -12.8 & -2.5 & -1.4 & -0.1 & -0.6 & 0.5 \\
\hline TXLG & -96.848 & 29.917 & -12.3 & -2.4 & -2.2 & 0.0 & 0.2 & -1.1 \\
\hline TXMX & -96.524 & 31.595 & -13.7 & -2.0 & -0.7 & 0.3 & 0.5 & 0.9 \\
\hline TXNA & -96.539 & 32.042 & -12.6 & -2.5 & -0.8 & 0.2 & 0.0 & 0.9 \\
\hline TXNC & -94.669 & 31.668 & -13.1 & -1.5 & -1.7 & -0.3 & 0.4 & 0.3 \\
\hline TXPI & -95.595 & 31.724 & -13.2 & -2.2 & -2.2 & -0.4 & 0.0 & -0.3 \\
\hline TXPV & -96.619 & 28.638 & -11.9 & -2.4 & -1.0 & 0.1 & 0.2 & 0.2 \\
\hline TXRU & -95.126 & 31.785 & -12.6 & -2.1 & -2.0 & 0.2 & 0.0 & 0.0 \\
\hline TXS1 & -94.128 & 31.526 & -13.1 & -1.5 & -2.2 & -0.4 & 0.2 & -0.1 \\
\hline TXSE & -97.998 & 29.591 & -12.0 & -3.0 & -0.3 & 0.2 & 0.1 & 0.8 \\
\hline TXSM & -97.903 & 29.878 & -12.2 & -2.5 & 0.1 & 0.1 & 0.5 & 1.2 \\
\hline TXTA & -97.445 & 30.564 & -12.6 & -2.9 & -1.1 & -0.1 & -0.1 & 0.2 \\
\hline TXWA & -97.111 & 31.578 & -12.4 & -3.0 & -1.9 & 0.4 & -0.2 & -0.4 \\
\hline \multicolumn{3}{|c|}{ Root Mean Square } & 12.6 & 2.4 & 1.7 & 0.3 & 0.3 & 0.8 \\
\hline
\end{tabular}

Table 2. Seven Parameters for Realizing Houston 20.

\begin{tabular}{llr}
\hline Parameters* $^{*}$ & Units & IGS14 to Houston20 \\
\hline$t_{0}$ & year & 2016.0 \\
$T_{x}^{\prime}$ & $\mathrm{m} \mathrm{yr}^{-1}$ & $1.4040400 \times 10^{-2}$ \\
$T_{y}^{\prime}$ & $\mathrm{m} \mathrm{yr}^{-1}$ & $9.6139040 \times 10^{-4}$ \\
$T_{z}^{\prime}$ & $\mathrm{m} \mathrm{yr}^{-1}$ & $7.2404862 \times 10^{-3}$ \\
$R_{x}^{\prime}$ & radian yr $^{-1}$ & $-9.8590126 \times 10^{-10}$ \\
$R_{y}^{\prime}$ & radian yr $^{-1}$ & $-1.7311089 \times 10^{-9}$ \\
$R_{z}^{\prime}$ & radian yr & $1.3205311 \times 10^{-9}$ \\
\hline
\end{tabular}

* Seven parameters are used to transform ECEF-XYZ coordinates from IGS14 to Houston20 according to Eq. (1). Counterclockwise rotations of the $x, y$, and $z$ axes are positive.

To study ground deformation at the Earth's surface, firstly, the ECEF-XYZ coordinates are transformed to Houston20 from original IGS14; secondly, the geocentric $X Y Z$ coordinates are converted to a geodetic orthogonal curvilinear coor- dinate system (longitude, latitude, and ellipsoid height) referencing the GRS80 ellipsoid; thirdly, the longitude and latitude coordinates are projected to a two-dimensional (2D) local horizontal plane for tracking surface ground deformation in the north-south (NS) and east-west (EW) directions at each site. The change of ellipsoid heights over time is used to depict the vertical displacement (subsidence or uplift). In practice, the vertical displacements derived from ellipsoid heights retain the same measurements as those derived from orthometric heights (Wang and Soler, 2014).

\subsection{Stability of Houston20}

The stability of a reference frame determines its ability to extrapolate station coordinates accurately into the past and the future beyond the frame range. Since blocks of the Earth's crust are not strictly rigid, it is a challenge to establish stable regional reference frames. To the most stringent users, the stability of a reference frame defines the essence of a suc- 
cessful reference frame. In practice, the stability or precision of a regional reference frame is often evaluated by the average velocity (root-mean-square) of all reference stations with respect to the reference frame (e.g., Blewitt et al., 2013).

The useful lifetime of a regional reference frame depends on its stability. According to our previous investigations, the root-mean-square (RMS) accuracy of the PPP daily solutions is about 3 to $4 \mathrm{~mm}$ in the horizontal directions and 6 to $8 \mathrm{~mm}$ in the vertical direction within the Greater Houston region (e.g., Yu and Wang, 2017; Wang et al., 2017). For Houston20, the frame range is approximately 10 years from 2010 to 2019. According to the statistics listed in Table 1, the stability of Houston 20 is at a level of $0.3 \mathrm{~mm} \mathrm{yr}^{-1}$ in the horizontal directions and approximately $0.8 \mathrm{~mm} \mathrm{yr}^{-1}$ in the vertical direction. The reference frame may result in an accumulated positional-error (uncertainty) of $3 \mathrm{~mm}$ in the horizontal directions and $8 \mathrm{~mm}$ in the vertical direction over a 10 year period, which are comparable with the RMS-accuracy (repeatability) of the PPP daily solutions. That is to say, the regional reference can be confidently used for approximately 10 years beyond the frame window (2010-2019) without causing positional errors larger than the accuracy of daily PPP solutions. Nevertheless, special attention should be drawn when applying Houston20 for delineating ground deformation at a submillimeter per year level. The stability of the regional reference frame may be further improved in future updates when a longer time span of observations and more reference stations become available.

\section{Subsidence derived from GPS observations (2010-2019)}

Long-term GPS observations accumulated by HoustonNet provide fundamental datasets for delineating spatial and temporal variations of ground deformation over time and space. Figure 3 illustrates the subsidence history at several sites located in the subsidence and groundwater regulation zones within the Greater Houston region. The locations of these sites are marked in Fig. 4. HGSD is divided into three regulatory areas: Area 1, Area 2, and Area 3. FBSD is divided into two regulatory areas: Area A and Area B. The Richmond/Rosenberg $(\mathrm{R} / \mathrm{R})$ area is a sub-area within the regulatory Area A. PAM station PA01 is located in Jersey Village, a northwest suburb within the HGSD regulatory Area 3, which was not scheduled for a $30 \%$ groundwater withdrawal reduction until 2011. PA01 recorded substantial subsidence $(\sim 4$ to $5 \mathrm{~cm} \mathrm{yr}^{-1}$ ) before the 2000s. The subsidence rate reduced to about 2 to $3 \mathrm{~cm} \mathrm{yr}^{-1}$ during the 2000s, and further reduced to 1 to $2 \mathrm{~cm} \mathrm{yr}^{-1}$ during the 2010s (Fig. 3a). The reduction of the overall subsidence rates within the Greater Houston Region is attributed to the reduction of groundwater withdrawals due to HGSD and FBSD regulations (e.g., Yu et al., 2014; Shah et al., 2018).
Vertical displacement time series with respect to Houston20
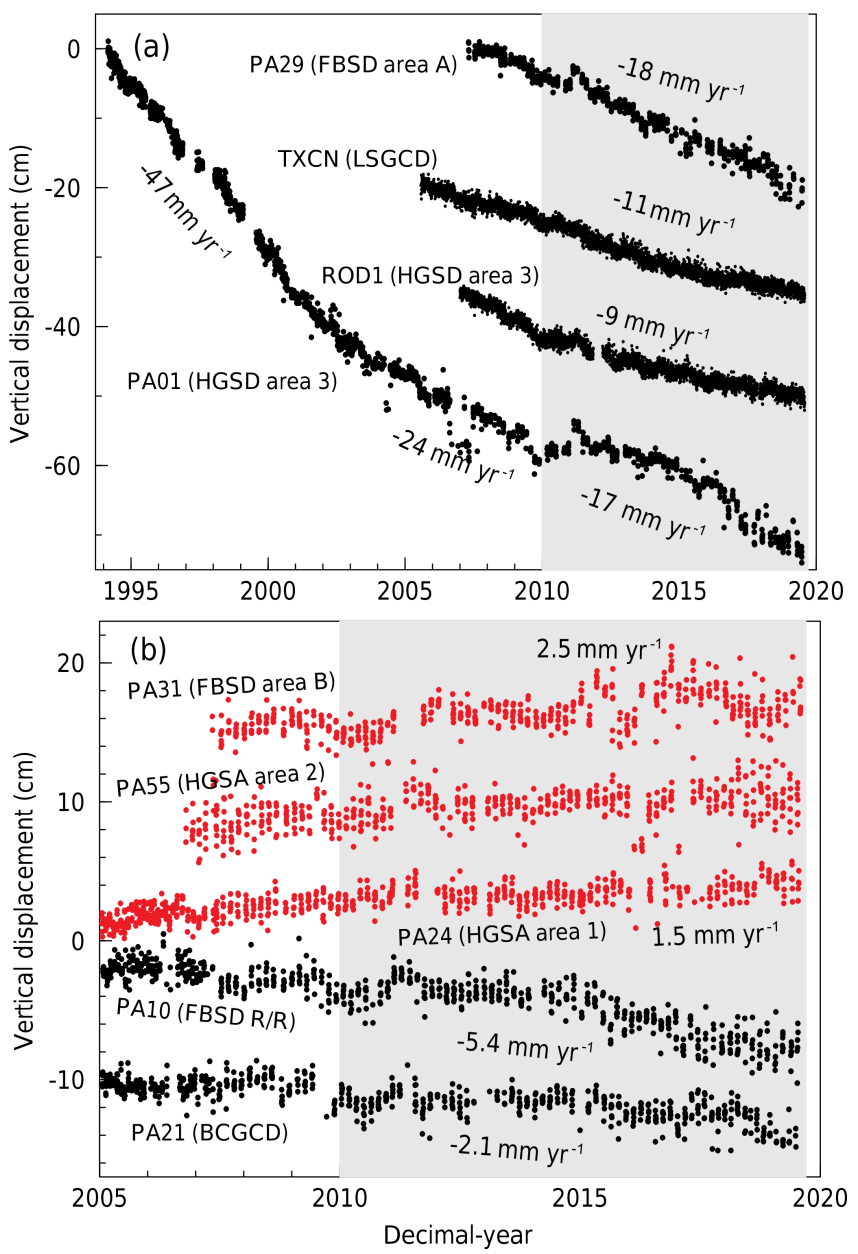

Figure 3. Subsidence (black) and uplift (red) time series at typical GPS sites located in different groundwater regulation zones within the Greater Houston region.

The subsidence time series illustrated in Fig. 3a indicate that subsidence rate varies considerably over time and space. The main reasons causing the spatial and temporal variations include: differences among sites in the ratios of sand, silt, and clay; differences of previously established pre-consolidation heads over space; and differences in rates and amount of groundwater withdrawal over space and time. In general, subsidence associated with groundwater pumping does not follow a strict linear trend over a long-term period (e.g., $>10$ years) (Fig. 3a). However, a linear trend is still an efficient tool for assessing subsidence over a time span between five to ten years (Wang et al., 2017). Figure 4 illustrates the estimated subsidence-rate contours and horizontal velocity vectors derived from GPS observations during the last decade (2010-2020). The velocities are referred to Houston20. The contour map clearly depicts a spatial pattern of the ongoing subsidence. Subsidence in downtown Houston and Galveston County (HGSD Areas 1,2) has ceased; slight 


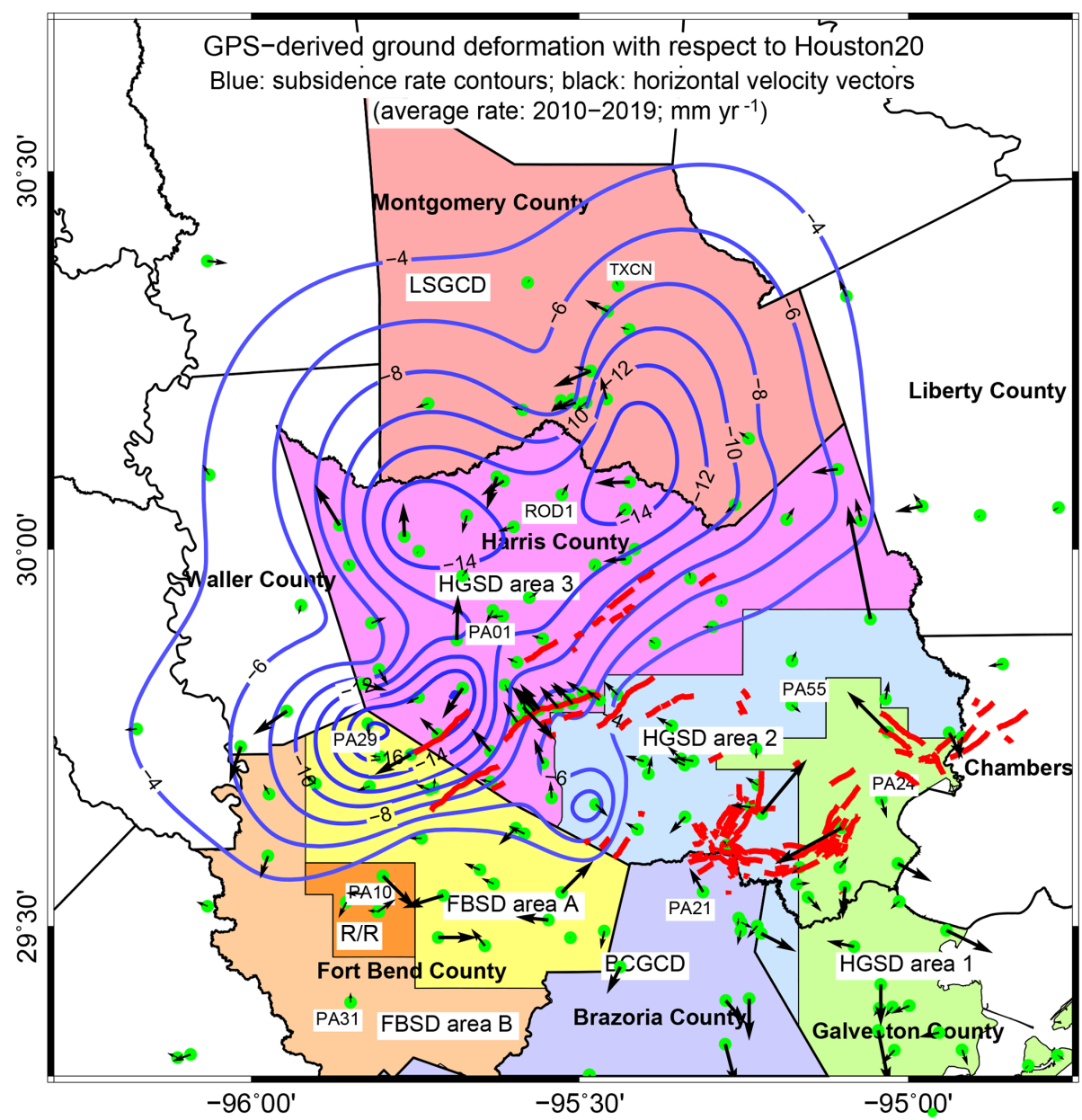

Figure 4. Map depicting subsidence-rate contours ( $\mathrm{mm} \mathrm{yr}^{-1}$ ) and horizontal velocity vectors (with respect to Houston20) derived from GPS observations within the period from 2010 to 2019. The colored areas represent the groundwater regulation zones.

land rebound ( $\sim 1$ to $3 \mathrm{~mm} \mathrm{yr}^{-1}$ ) has been recorded at several sites located in HGSD Area 1, Area 2, and FBSD Area B (Fig. 3b). However, rapid subsidence $\left(>1 \mathrm{~cm} \mathrm{yr}^{-1}\right)$ is occurring in The Woodlands (LSGCD), Jersey Village and Spring (HGSD Area 3), and Katy (FBSD Area A) areas. Moderate subsidence (between $4 \mathrm{~mm} \mathrm{yr}^{-1}$ and $1 \mathrm{~cm} \mathrm{yr}^{-1}$ ) is taking place in a large part of Montgomery County, northwest Harris County, and Fort Bend County (Fig. 4).

The horizontal velocity vectors depicted in Fig. 4 suggest that only a few sites experienced localized horizontal movements larger than $1 \mathrm{~mm} \mathrm{yr}^{-1}$ over the past decade. Several GPS stations adjacent to fault lines show approximately 3 to $5 \mathrm{~mm} \mathrm{yr}^{-1}$ horizontal motions, which may be associated with localized faulting and subsidence activities. The applications of the regional geodetic infrastructure in urban faulting studies are illustrated in a recent article (Liu et al., 2019).

\section{Summary and Conclusions}

This study summarized the geodetic infrastructure in the Greater Houston region. The primary product from this study is the determination of the seven parameters (Table 2) needed for converting the ECEF-XYZ positional coordinates from IGS14 to Houston20. The regional geodetic infrastructure provides a consistent platform for studying local ground deformations over space and time and serves the broad research and surveying communities. For example, geologists and hydrologists may apply HoustonNet data and the regional reference frame to study ground deformation due to faulting, salt dome uplift, drought, aquifer deformation, seasonal hydrologic and atmospheric pressure loading; meteorologists may use HoustonNet data to study regional water vapor profiles that are critically important for improving numerical weather prediction models for forecasting hurricanes; civil engineers may apply the rigorous reference frame to conduct long-term structural health monitoring for critical structures, such as high-rise buildings, highway bridges, dams, and levees. The 
regional geodetic infrastructure also makes it possible to integrate observations from different remote sensing techniques (e.g., GPS, InSAR, LiDAR, Photogrammetry) to a unified geodetic reference and enables multidisciplinary and crossdisciplinary research.

The frame stability of Houston 20 is approximately $0.3 \mathrm{~mm} \mathrm{yr}^{-1}$ in the horizontal directions and $0.8 \mathrm{~mm} \mathrm{yr}^{-1}$ in the vertical direction. Houston 20 can be confidently used for 10 years beyond the frame window from 2010 to 2019. Special attention should be drawn when applying Houston 20 for delineating sub-millimeter per year ground deformation. The regional reference frame will be incrementally improved and synchronized with future updates of IGS reference frames.

Data availability. Raw GPS datasets applied for this study are available to the public through the data archive facilities at HarrisGalveston Subsidence District (https://hgsubsidence.org, last access: 8 March 2020), UNAVCO (https://www.unavco.org/data, last access: 8 March 2020), National Geodetic Survey of U.S. (http://geodesy.noaa.gov/CORS, last access: 8 March 2020), and Texas Department of Transportation (http://ftp.dot.state.tx.us/pub/ txdot-info/isd/gps/RINEX, last access: 8 March 2020).

Author contributions. GA and GW prepared the original draft. All authors edited, reviewed, and improved the manuscript.

Competing interests. The authors declare that they have no conflict of interest.

Special issue statement. This article is part of the special issue "TISOLS: the Tenth International Symposium On Land Subsidence - living with subsidence". It is a result of the Tenth International Symposium on Land Subsidence, Delft, the Netherlands, 17-21 May 2021.

Acknowledgements. The authors acknowledge UNAVCO for archiving GPS data from the HoustonNet stations operated by the University of Houston. This study was supported by the University of Houston and the Harris Galveston Subsidence District. Yan Bao's research at the University of Houston was supported by the Beijing University of Technology and the National Science Foundation of China (No. 51829801).

\section{References}

Bertiger, W., Desai, S., Haines, B., Harvey, N., Moore, A., Owen, S., and Weiss, J.: Single receiver phase ambiguity resolution with GPS data, J. Geodesy, 84, 327-337, https://doi.org/10.1007/s00190-010-0371-9, 2010.

Blewitt, G., Kreemer, C., Hammond, W. C., and Goldfarb, J. M.: Terrestrial reference frame NA12 for crustal defor- mation studies in North America, J. Geodyn., 72, 11-24, https://doi.org/10.1016/j.jog.2013.08.004, 2013.

Huffman Jr., A. C., Kinney, S. A., Biewick, L., Mitchell, H. R., and Gunther G. L.: Salt diapirs in the Gulf Coast, from Gulf Coast Geology (GCG) Online - Miocene of Southern Louisiana, Version 1, DS-90-A, US Geological Survey, Reston, VA, USA, available at: https://pubs.usgs.gov/ds/2004/90/A (last access: 8 March 2020), 2004.

Kasmarek, M. C. and Ramage, J. K.: Water-level altitudes 2017 and water-level changes in the Chicot, Evangeline, and Jasper aquifers and compaction 1973-2016 in the Chicot and Evangeline aquifers, Houston Galveston region, Texas, U.S. Geological Survey Scientific Investigations Report 2017-5080, https://doi.org/10.3133/sir20175080, 2017.

Kearns, T. J., Wang, G., Bao, Y., Jiang, J., and Lee, D.: Current land subsidence and groundwater level changes in the Houston metropolitan area, Texas (2005-2012), J. Surv. Eng., 141, 1-16, https://doi.org/10.1061/(ASCE)SU.1943-5428.0000147, 2015.

Kearns, T. J., Wang, G., Turco, M., Welch, J., Tsibanos, V., and Liu, H.: Houston16: A stable geodetic reference frame for subsidence and faulting study in the Houston metropolitan area, Texas, US., Geod. Geodyn., 10, 382-293, https://doi.org/10.1016/j.geog.2018.05.005, 2019.

Liu, Y., Sun, X., Wang, G., Turco, M. J., Agudelo, G., Bao, Y., Zhao, R., and Shen, S.: Current activity of the Long Point Fault in Houston, Texas constrained by continuous GPS measurements (2013-2018), Remote Sens., 11, 1213, https://doi.org/10.3390/rs11101213, 2019.

Qu, F., Lu, Z., Jin-Woo, K., and Zheng, W.: Identify and monitor growth faulting using InSAR over the Northern Greater Houston, Texas, USA, Remote Sens., 11, 1498, https://doi.org/10.3390/rs11121498, 2019.

Rebischung, P., Altamimi, Z., Ray, J., and Garayt, B.: The IGS contribution to ITRF2014, J. Geodesy, 90, 611-630, https://doi.org/10.1007/s00190-016-0897-6, 2016.

Shah, S. D. and Lanning-Rush, J.: Principal faults in the Houston, Texas, metropolitan area, US Department of the Interior: Washington, DC, USA, US Geological Survey, Reston, VA, USA, available at: https://pubs.usgs.gov/sim/2005/2874 (last access: 8 March 2020), 2005.

Shah, S. D., Ramage, J. K., and Braun, C. L.: Status of groundwaterlevel altitudes and long-term groundwater-level changes in the Chicot, Evangeline, and Jasper aquifers, Houston-Galveston region, Texas, 2018, No 2018-5101, 18 p., U.S. Geological Survey, Reston, USA, available at: https://doi.org/10.3133/sir20185101 (last access: 8 March 2020), 2018.

Turco, M. J. and Petrov, A.: Effects of groundwater regulation on aquifer-system compaction and subsidence in the HoustonGalveston Region, Texas, USA, Proc. IAHS, 372, 511-514, https://doi.org/10.5194/piahs-372-511-2015, 2015.

Wang, G., Bao, Y., Gan, W., Geng, J., Xiao, G., and Shen, J. S.: NChina16, a stable geodetic reference frame for geological hazard studies in North China, J. Geodyn., 115, 10-22, https://doi.org/10.1016/j.jog.2018.01.003, 2018.

Wang, G., Liu, H., Mattioli, G. S., Miller, M. M., Feaux, K., and Braun, J.: CARIB18, a stable geodetic reference frame for geological hazard monitoring in the Caribbean region, Remote Sens., 11, 680, https://doi.org/10.3390/rs11060680, 2019. 
Wang, G. and Soler, T.: Measuring land subsidence using GPS: ellipsoid height vs. orthometric height, J. Surv. Eng., 141, 1-12, https://doi.org/10.1061/(ASCE)SU.1943-5428.0000137, 2014.

Wang, G., Turco, M., Soler, T., Kearns, T., and Welch, J.: Comparisons of OPUS and PPP solutions for subsidence monitoring in the greater Houston area, J. Surv. Eng., 143, 05017005 , https://doi.org/10.1061/(ASCE)SU.1943-5428.0000241, 2017.

Wang, G., Yu, J., Ortega, J., Saenz, G., Burrough, T., and Neill, R.: A stable reference frame for ground deformation study in the Houston metropolitan area, Texas, J. Geod. Sci., 3, 188-202, https://doi.org/10.2478/jogs-2013-0021, 2013.

Wang, G., Zhou, X., Wang, K., Ke, X., Zhang, Y., Zhao, R., and Bao, Y.: GOM20, a stable geodetic reference frame for subsidence, faulting, and sea-level rise studies along the coast of the Gulf of Mexico, Remote Sens., 12, 350, https://doi.org/10.3390/rs12030350, 2020.
Yu, J. and Wang, G.: Introduction to the GNSS geodetic infrastructure in the Gulf of Mexico Region, Surv. Rev., 352, 51-65, https://doi.org/10.1080/00396265.2015.1108069, 2017.

Yu, J., Wang, G., Kearns, T. J., and Yang, L.: Is there deep- seated subsidence in the Houston-Galveston area?, Int. J. Geophys., 2014, 1-11, https://doi.org/10.1155/2014/942834, 2014.

Zilkoski, D. B., Hall, L., Mitchell, G., Kammula, V., Singh, A., Chrismer, W., and Neighbors, R.: The Harris-Galveston coastal subsidence district/national geodetic survey automated global positioning system subsidence monitoring project, Proc., U.S. Geological Survey Subsidence Interest Group Conf., USGS OpenFile Report, 308, 13-28, 2003. 